\title{
Early Analysis of Peripheral Obstructive Arterial Disease in Patients with Diabetes Mellitus in Primary Care Setting in Kuantan, Malaysia: Are There Differences?
}

Norhayati binti Ab Hamid ${ }^{1}$, Nur Diyana Khairul Anuar ${ }^{1}$, Syahir Muhaimin Md Salleh ${ }^{1}$, Ahmad Faidzal Othman ${ }^{1}$, Mohd Norhisham Azmi Abdul Rahman", Jamalludin Bin Ab.Rahman ${ }^{2}$, Azrin Waheedy Ahmad ${ }^{1}$, Noor Ezmas Mahno ${ }^{1}$

${ }^{1}$ Department of Surgery, Kulliyyah of Medicine, International Islamic University Malaysia

${ }^{2}$ Department of Community Medicine, Kulliyyah of Medicine, International Islamic University Malaysia

Presenter: Nur Diyana Khairul Anuar

Introduction: Diabetes mellitus is a known risk factor for the development of Peripheral Obstructive Arterial Disease (POAD). POAD is also one of the major cause of limb loss in diabetic patients. Yet, there is no Ankle-Brachial Index ( $A B I)$ screening among the diabetic population to quantify the disease burden or detect the disease at an early stage. This study aimed to find out the prevalence of POAD among diabetic patients in primary care and the associated risk factors and its implication on their quality of life. Materials and Methods: Ninety diabetic patients were included in this universal survey at Klinik Kesihatan (KK) Jaya Gading. ABI of lower than 0.9 was used to define POAD. A validated WHO-QOL BREF Malay version was used to assess the Quality of Life. Results: The prevalence of POAD among diabetic patients in KK Jaya Gading, Kuantan was found to be $20 \%$. Age was a significant risk factor $(p=0.005)$. Social domain of the Quality of Life was significantly affected in patients with POAD. Conclusion: The prevalence of POAD among diabetics in the primary care was relatively high and this supports early screening to prevent further deterioration. 